\title{
Covid-19 and inequality: developing an age-friendly strategy for recovery in low income communities
}

Tine Buffel, Patty Doran, Mhorag Goff, Luciana Lang, Camilla Lewis, Chris Phillipson and Sophie Yarker

\begin{abstract}
Purpose - This paper aims to explore the social impact of the COVID-19 pandemic, focusing on issues facing older people living in urban areas characterised by multiple deprivation.

Design/methodology/approach - The paper first reviews the role of place and neighbourhood in later life; second, it examines the relationship between neighbourhood deprivation and the impact of COVID-19; and, third, it outlines the basis for an "age-friendly" recovery strategy.

Findings - The paper argues that COVID-19 is having a disproportionate impact on low-income communities, which have already been affected by cuts to public services, the loss of social infrastructure and pressures on the voluntary sector. It highlights the need for community-based interventions to be developed as an essential part of future policies designed to tackle the effects of COVID-19.
\end{abstract}

Originality/value - The paper contributes to debates about developing COVID-19 recovery strategies in the context of growing inequalities affecting urban neighbourhoods.

Keywords Austerity, Social inequality, Social exclusion, Older people, COVID-19, Ageing populations, Deprived neighbourhoods

Paper type Research paper

\section{Introduction}

This paper aims to explore the social impact of the COVID-19 pandemic, focusing on issues facing older people living in urban areas characterised by multiple deprivation. The discussion contributes to debates about developing COVID-19 recovery strategies in the context of growing inequalities affecting urban neighbourhoods. The paper argues that COVID-19 is having a disproportionate impact on low-income communities, which have already been affected by cuts to public services, the loss of social infrastructure, and pressures on the voluntary sector. The discussion first reviews the role of place and neighbourhood in later life; second, examines the relationship between neighbourhood deprivation and the impact of COVID-19; and, third, outlines the basis for an "age-friendly" recovery strategy. The paper highlights the need for community-based interventions to be developed as an essential part of future policies designed to tackle the effects of COVID-19. COVID-19, it is argued, presents a major challenge to developing what has been termed "age-friendly" cities and communities (Buffel et al., 2018). The paper argues that work in this area will need to re-orientate to the issues raised by communities being re-shaped by policies to mitigate COVID-19 but in the context of the continuing effects of austerity on the range and quality of public services.
All authors are part of the Manchester Urban Ageing Research Group (MUARG) at the University of Manchester, UK. Tine Buffel, Patty Doran, Mhorag Goff and

Luciana Lang are all based at the University of Manchester, Manchester, UK. Camilla Lewis is based at Newcastle University, Newcastle upon Tyne, UK. Chris Phillipson and Sophie Yarker both are based at the University of Manchester, Manchester, UK.

Received 11 September 2020 Revised 13 October 2020 Accepted 13 October 2020

(C) Tine Buffel, Patty Doran, Mhorag Goff, Luciana Lang, Camilla Lewis, Chris Phillipson and Sophie Yarker. Published by Emerald Publishing Limited. This article is published under the Creative Commons Attribution (CC BY 4.0) licence. Anyone may reproduce, distribute, translate and create derivative works of this article (for both commercial and non-commercial purposes), subject to full attribution to the original publication and authors. The full terms of this licence may be seen at http:// creativecommons.org/licences/ by/4.0/legalcode

Funding: This work was supported by the Economic and Social Research Council (ESRC) under the Future Research Leaders scheme (Grant No: ES/N002180/1), the Centre for Ageing Better, Greater Manchester Centre for Voluntary Organisation, and Age-Friendly Manchester. 


\section{Where we live matters greatly for how we age}

Older people have been disproportionately affected by COVID-19, whether in hospital, the community, or in care homes. The coronavirus crisis has itself coincided with a period of deepening inequalities, brought about by cuts to key resources affecting many of the neighbourhoods in which older people live (Yarker, 2019). This dimension has assumed particular importance given the importance of the home and immediate community as factors influencing the quality of daily life in older age.

The meaning of, and attachment to, home and place is considered especially significant for older people for a number of reasons: first, the long period of time likely to have been spent in the same locality (Phillipson, 2007); second, the greater time spent at home following retirement, reflecting changing patterns of spatial use (Peace et al., 2007); third, increased reliance upon community relationships for support in later life (Thomése et al., 2018); and, fourth, the significance of place in preserving a sense of identity and independence in old age (Rowles, 1978).

Therefore, where we live also matters for how we age in place. Experiences of place vary greatly between individuals, influenced by various demographic, economic and social factors. For some older people, especially those living in areas of multiple deprivation, being "stuck in place" (Smith et al., 2018) may be a better descriptor than "ageing in place" (Wiles et al., 2012), with the absence of suitable alternatives forcing people to remain in their current home, despite threats posed by changes to their neighbourhood. This may be a particular problem in those areas affected by the physical deterioration of housing and the outdoor environment, high levels of crime, and a decline of social infrastructure in the form of libraries, community centres, and shops (Yarker, 2019).

Scharf et al. (2002) interviewed 600 people aged 60 and over living in inner-city communities in Liverpool, London, and Manchester. Their study found that older people were "excluded" from many of the organisations and institutions which contributed to a better quality of life in their neighbourhoods. Poverty was a major feature of daily life, affecting nearly half of those interviewed which resulted in the exclusion of many residents from participating within their communities. Moreover, a significant minority of older people were identified as socially isolated and/or severely lonely.

A study among older migrants living in low-income neighbourhoods in Belgium and the UK illustrated the range of structural barriers facing ethnic minority groups, with a particular focus on the role of poverty, poor housing conditions, language barriers, and lack of access to services and facilities (Buffel and Phillipson, 2016). Research by De Noronha (2019) in the UK found that ethnic minorities experience significantly higher levels of housing deprivation than white British older people, with Bangladeshi and black Africans most likely to be experiencing overcrowding, a lack of central heating, or sharing of kitchen or bathroom (see, also, Ahmed, 2020). In general, inequality is becoming a more complex issue, and more entrenched in some cases, given the increasing diversity of populations within urban neighbourhoods (Cooper and Whyte, 2017).

\section{Neighbourhood inequality and Covid-19}

Richard Horton (2020: 48) makes the point that COVID-19 is not socially neutral, describing how: "Coronavirus exploits and accentuates inequality". Older people living in areas affected by deprivation may, we would argue, experience a double lockdown - suffering the effects of enforced social isolation whilst living in places affected by substantial cuts to public services.

Evidence gathered over the past decade reveals an increase in levels of inequality between neighbourhoods. The Marmot Review, which traced changing health inequalities between 2010 and 2020 documented the rise in deprivation affecting many 
parts of England. Marmot highlighted the problems facing "left behind" and "ignored communities" which were experiencing long-term deprivation: "Over the last 10 years, these [...] communities and areas have seen vital physical and community assets lost, resources and funding reduced, community and voluntary sector services decimated and public services cut, all of which have damaged health and widened inequalities. These lost assets and services compound the multiple economic and social deprivations, including high rates of persistent poverty and low income, high levels of debt, poor health and poor housing that are already faced by many residents." (Marmot et al., 2020, p. 94).

Similar conclusions can be made in relation to the situation facing older people living in areas of multiple deprivation. Research based on the English Longitudinal Study of Ageing (ELSA) demonstrated a causal relationship between area deprivation and social exclusion in later life. The study revealed that older people living in deprived urban neighbourhoods had the highest levels of social exclusion compared with less deprived neighbourhoods, with evidence suggesting that this stems from barriers experienced across a range of domains such as access to services and amenities, social relationships, and civic, cultural and leisure participation (Prattley et al., 2020).

Neighbourhood-based inequalities have deepened and amplified in the context of COVID-19, with people (of all ages) living in the poorest parts of England and Wales dying at twice the rate from COVID-19 compared with those in more affluent areas (Office for National Statistics ONS, 2020a). There are also widening inequalities between ethnic groups, with research from the Office for National Statistics ONS (2020b) showing that, when taking age into account, Black males were 4.2 time more likely to die from a COVID-19-related death than White males. The risk was also pronounced for South Asian and mixed-ethnic groups. Public Health England (2020) suggest that the key factors influencing widening inequalities include: living in urban areas; in overcrowded households; in deprived areas; and working in high-risk occupations.

Important questions arise from the current crisis affecting communities, these including: Will the pandemic result in the gap between poorer and richer areas increasing even further? Will certain social groups be left behind in measures to mitigate the consequences of COVID-19? Research commissioned by Public Health England suggests that organisations embedded in local areas are particularly well placed to work with individuals and communities in order to identify those at risk of social isolation, and to engage them in finding solutions for developing new types of support (Durcan and Bell, 2015). However, this is likely to be especially challenging given cuts to social infrastructure in the form of community centres, leisure centres, and libraries. As a result, many older people living in deprived neighbourhoods are at risk of being isolated from the spaces and networks of support and social connection essential to their wellbeing and sense of belonging (Yarker, 2019). The term "prisoners of space" used by Graham Rowles (1978), in his research on the geographical experiences of older people, has acquired renewed meaning in the context of the COVID-19 lockdown. For older people living in low income communities, who were already more at risk of social isolation before the pandemic, the term "being stuck in place" has undoubtedly become a better descriptor than that of "ageing in place".

The loss of vital social infrastructure raises fundamental questions about the changing nature of our communities, and the responses needed to assist older people during the pandemic. With the likely continuation of social distancing rules in some form in the near future, the role of neighbourhood support requires urgent attention. COVID-19 and measures such as social distancing will "stress test" the ability of communities to work together to protect vulnerable groups. The pandemic underlines the degree to which social processes relating to inequality, discrimination and racism contribute to the distribution of illness and deaths caused by COVID-19. Social interventions in marginalised communities are now urgently required to strengthen the defences of residents, so they are protected against subsequent waves of the virus. The next section of this paper sets out the basis for recovery planning from the effects of COVID-19. 


\section{Discussion: developing age-friendly recovery planning}

The range of inequalities reviewed in this paper suggests a challenge to the implementation of policies designed to create what has been termed "age-friendly communities". Such work has become a significant area of activity over the past decade, following the inauguration by the World Health Organization (in 2010) of the Global Network of Age Friendly Cities and Communities. The result has been interventions in, areas such as housing in later life, transportation, outdoor spaces, and social participation. Many of the leading cities in the UK are developing age-friendly initiatives, supported by the UK Network of Age-Friendly Communities [1]. However, their scope was already being affected by economic pressures on local authorities and voluntary bodies, these likely to become even more severe given the impact of COVID-19. Notwithstanding such difficulties, we think that the age-friendly model can provide a viable framework for developing new approaches to support people and communities during the pandemic. In what follows, we sketch out an agenda based around five main themes:

1. prioritising areas of multiple deprivation in future government spending;

2. developing locally based partnerships working across organisational boundaries;

3. challenging social inequality, stigma, and discrimination;

4. changing the narrative on ageing and combatting ageism; and

5. integrating social science research with policy.

\section{Extra funding to assist deprived neighbourhoods}

A significant limitation in the Government's response to the pandemic has been the failure to provide aid to the UK's poorest communities. These areas have been hit especially hard by 10 years of austerity, with poorest communities bearing the brunt of the almost $£ 900 \mathrm{~m}$ cuts to public health over the period 2014-2019 (Institute for Public Policy Research (IPPR), 2019). Cuts to local authorities over the past decade have resulted in significant financial pressures on public services. Local authorities suffered a $49.1 \%$ real terms reduction in central government funding from 2010 to 2018 (UK Parliament, 2019). The lockdown has also had a significant impact on the fund-raising activities of charities. The voluntary sector lost an estimated $£ 4.3 \mathrm{bn}$ income during the first quarter of 2020, a reduction likely to have a significant impact on support available to poorer communities [2].

Areas of multiple deprivation must be prioritised in future government spending. Such funding will need to be complemented by a national strategy to tackle health inequalities, drawing on lessons from the Marmot Review (2020), and studies showing the detrimental impact of neighbourhood deprivation on older people's quality of life (Prattley et al., 2020). Working with older people to combat social isolation (Cotterell et al., 2018), by focusing resources on socially excluded places, must be an essential part of the recovery strategy. We argue that the Government should create a 'Communities in Crisis fund' bringing together new and existing sources of support, working with local authorities to increase resources directed at the most vulnerable neighbourhoods.

\section{Encouraging place-based partnerships and multi-sectorial collaboration}

The COVID-19 pandemic has already produced examples of joined-up working across sectors and organisational boundaries, with efforts to support marginalised groups who are self-isolating at home. New ways of connecting and collaborating must be created in response to the impact of measures such social distancing. In Greater Manchester, the majority of Age UK branches have moved their services online or by telephone, with branches trialling new approaches to addressing social isolation. Voluntary bodies running 
food banks have moved towards direct services, co-ordinating and providing food parcels, and managing volunteers. Organisations representing ethnic minorities have developed informative videos for a number of communities for whom English is not their first language, and would therefore miss out on important information about COVID-19 [3].

Coordination of services and innovative collaborations within and across organisations are essential - at every level - to maximize collective efforts and make the most of the limited resources available. Local government, despite financial pressures, is in a unique position to initiate and advance such initiatives, and has a critical role to play as place-based conveners of local agencies to jointly develop community recovery plans. Urgent attention should be given to new models of neighbourhood working as part of their recovery strategies. Such ways of working will encompass a variety of approaches, for example: advocacy, befriending, counselling, and organising social activities. These types of support have become essential in the current crisis and need to be strengthened over the longer-term. Given the extent of the crisis affecting communities, a broader range of activities at a neighbourhood level should be encouraged, including: supporting the development of food co-operatives, low-cost home repair services, financial advice, re-invigorating "third spaces" (such as cafés and community centres), and facilitating community leadership (Goff et al., 2020).

\section{Challenging discrimination, social stigma and inequality}

COVID-19 is disproportionally affecting groups who are already disadvantaged on the basis of age, race, ethnicity, gender, disability and sexual orientation. There is evidence, for example, that the pandemic is exacerbating gender inequalities. While men are more likely to die from coronavirus, research suggests that the social and economic toll will be paid, disproportionally, by women. A recent United Nations (2020) report exploring gender inequality in the context of COVID-19 highlighted a spike in domestic violence as women are "sheltering-in-place" with their abusers; the loss of employment for women who hold the majority of insecure, informal and low-paid jobs; the risk shouldered by care workers, who are predominantly women; and the rapid increase in unpaid work that women overwhelmingly provide already.

There is also strong evidence, as already noted, that increased ethnic inequalities in COVID-19-related complications and deaths exist in the UK and elsewhere (Becares and Nazroo, 2020; Kirby, 2020; Platt and Warwick, 2020), with ethnic minority people more vulnerable to, and experiencing poorer prognoses from, COVID-19 infection. There is also evidence that the COVID-19 outbreak has exacerbated social stigma and discriminatory behaviours against people of certain ethnic backgrounds (World Health Organization, 2020). Moreover, COVID-19 is exposing the various issues that marginalised groups of people are facing due to structural discrimination and isolation. The crisis is also intensifying the difficulties facing LGBTQ individuals and people with disabilities, many of whom face discrimination and stigma when seeking health care and are more vulnerable to violence and human rights abuses (ILGA-Europe, Equality for lesbian, gay, bisexual, trans and intersex people in Europe, 2020).

There is thus an urgent need for governments to work with national and local equalities organisations in developing COVID-19 recovery strategies to ensure support for people who are facing intersecting pressures relating to ageism, racism, sexism and inequality. Particular attention should be paid to older people from marginalised groups, whose experiences of discrimination are likely to be intensified by the pandemic.

\section{Changing the narrative on ageing and combatting ageism}

A review of the literature examining the impact of age-related stereotypes conducted a few months before the pandemic hit the UK showed that ageism is still rife, with one in three people experiencing age prejudice or age discrimination (Centre for Ageing Better, 2020). 
Dominant narratives around ageing centre around stereotypes of vulnerability and passivity, which have been further exacerbated by COVID-19. Those aged 70 and above have been depicted as frail, a burden, and presenting risks to other people. Increasingly, media discourse has also promoted the view that all older people are lonely and socially isolated. Contrary to this discourse, evidence suggests that loneliness and social isolation affects people of all ages, with some studies showing that young adults are at greater risk than older adults (ONS, 2018). In their statement on COVID-19, the British Society of Gerontology (2020) drew on various data sources including the English Longitudinal Study of Ageing and the Understanding Society Survey to summarise some of the vital, but often ignored, social roles that older people play in society:

\footnotetext{
Older people participate in paid work, run businesses, volunteer, are active in civil society and the cultural life of communities, and take care of family members including parents, spouses/ partners, adult children (especially those living with disabilities), and grandchildren. There are currently more than 360,000 people over 70 in paid work, including one in seven men between 70 and 75 and one in sixteen women. Almost one million people over the age of 70 provide unpaid care, including one in seven women in their 70s. One in five people aged between 70 and 85 , over 1.5 million people, volunteer in their communities. People in good health are especially likely to volunteer at older ages with almost a third of those in their early-70s doing so. Older adults should not be excluded but should be seen as a vital and necessary part of economic and community life. (British Society of Gerontology, 2020, p. 2)
}

The concern is, however, that the continuation of social distancing in some form (or a second wave of COVID-19) is likely to further reinforce ageism and age-based divisions within communities. The number of deaths (direct and indirect) in care homes from COVID-19, and the delay in recognising the extent of the disaster, illustrates the extent of the crisis in social attitudes towards ageing. Older people are increasingly presented as a burden, in relation to the economy, pensions and social care. Given the risk for greater age segregation occurring as a result of COVID-19, it is essential to foster opportunities for greater contact between generations, challenge ageist stereotypes, and highlight the diversity of experiences in later life. The task will be to support and strengthen ties across generations in order to develop an effective response to the present crisis.

\section{Integrating social science research with policy}

Finally, medical research into COVID-19 has increased exponentially for urgent and obvious reasons. In addition, this paper has also shown that social scientists have a crucial role to play in tackling the crisis, not only in improving our understanding of the immediate and long-term social impact of the virus and how it is disproportionally affecting sections of the population, but also in informing policy development and recovery planning. A key priority will be to create stronger dialogue between policy and researchers from multiple disciplinary perspectives, including the social sciences. A starting point must be to expand the priorities addressed by the Scientific Advisory Group for Emergencies (SAGE) which began meeting towards the end of January 2020 to discuss the implications of the virus. However, it will be essential to broaden the range of contributors of the committee if this is to be achieved. Older people and those in residential care in particular, were always likely to be amongst the group most affected by COVID-19. But SAGE has had limited contributions from social scientists or specialists either within gerontology or geriatric medicine, or, crucially, that of social care. As Anthony Costello, Professor of Global Health and Sustainable Development at UCL, commented, "The makeup of SAGE reflects an oddly skewed and overwhelmingly medical view of science". Without a stronger voice of social scientists in the debate, the risk is that the government's recovery strategy will ignore marginalised groups, who have already been disproportionally affected by COVID-19 and the lockdown. 


\section{Conclusion}

This analysis has explored the immediate social impacts and responses to the coronavirus, revealing urgent questions about how to develop strategies to support older people. Crucially, the pandemic is forcing us to re-think what kind of society we want to re-build or 'recover' in the decades ahead. COVID-19 has exposed, and exacerbated deep-rooted structural inequalities and injustices in our society. This paper has shown that it is important to add a social science perspective to the debate. Here, we would underline the relevance of Soja's (2010, p. 19) argument that the "...geographies in which we live can have both positive and negative effects on our lives". He writes, "They are not just dead background or a neutral physical stage for the human drama but are filled with material and imagined forces that can hurt us or help us in nearly everything we do, individually and collectively". He concludes, "This is a vitally important part of the new spatial consciousness, making us aware that the geographies in which we live can intensify and sustain our exploitation as workers, support oppressive forms of cultural and political domination based on race, gender, and nationality, and aggravate all forms of discrimination and injustice" (Soja, 2010, p. 19). Ensuring social and spatial justice for different groups of older people is now a crucial part of this debate. Developing a COVID-19 recovery strategy to address the needs of the most deprived neighbourhoods represents a key task for public policy.

\section{Notes}

1. www.ageing-better.org.uk/uk-network-age-friendly-communities

2. www.charitytimes.com/ct/coronavirus-charities-could-miss-out-on-billions-over-next-12-weeks.php

3. For further information on these and other initiatives, see: http://blog.policy.manchester.ac.uk/ growth_inclusion/2020/06/the-voluntary-and-community-sector-and-covid-19-going-to-war-withoutammunition/

\section{References}

Ahmed, N. (2020), Family, Citizenship and Islam: The Changing Experiences of Migrant Women Ageing in London, Routledge, London.

Becares, L. and Nazroo, J. (2020), "Racism, ethnicity, and COVID-19 related inequalities in the UK", in Brun, S. and Simon, P. (Eds), Issue 'Inégalités Ethno-Raciales et Pandémie de Coronavirus', De facto, available at: http://icmigrations.fr/2020/05/13/defacto-019-02/?lang=en

British Society of Gerontology (2020), "Covid-19: statement from the president and members of the national executive committee of the British society of gerontology", available at: https://ageingissues. wordpress.com/2020/03/21/covid-19-statement-from-the-president-and-members-of-the-nationalexecutive-committee-of-the-british-society-of-gerontology/

Buffel, T. and Phillipson, C. (2016), "Can global cities be 'age-friendly cities"? Urban development and ageing populations", Cities, Vol. 55, pp. 94-100.

Buffel, T., Handler, S. and Phillipson, C. (2018), Age-Friendly Cities and Communities: A Global Perspective, Policy Press, Bristol.

Centre for Ageing Better (2020), "Doddery but dear? Examining age-related stereotypes", available at: www.ageing-better.org.uk/sites/default/files/2020-03/Doddery-but-dear.pdf

Cooper, V. and Whyte, D. (2017), The Violence of Austerity, Pluto Press, London.

Cotterell, N., Buffel, T. and Phillipson, C. (2018), "Preventing social isolation in older people", Maturitas, Vol. 113, doi: 10.1016/j.maturitas.2018.04.014.

De Noronha, N. (2019), Housing and the Older Ethnic Minority Population in England, Race Equality Foundation \& Housing LIN, London.

Durcan, D. and Bell, R. (2015), Local Action on Health Inequalities: Reducing Social Isolation across the Lifecourse, Public Health England, London. 
Goff, M., Doran, P., Phillipson, C. and D'Andreta, D. (2020), Community Interventions to Promote 'Ageing in Place': Developing the 'Village' Model in Manchester, The University of Manchester, MICRA, available at: http://documents.manchester.ac.uk/display.aspx?DoclD=48721

Horton, R. (2020), "Its not too early to learn the lessons of a mismanaged response", The New Statesman, p. 48.

ILGA-Europe, Equality for lesbian, gay, bisexual, trans and intersex people in Europe (2020), "COVID-19 and specific impact on LGBTI people and what authorities should be doing to mitigate impact", available at: www.ilga-europe.org/sites/default/files/COVID19\%20_Impact\%20LGBTI\% 20people.pdf

Institute for Public Policy Research (IPPR) (2019), "Hitting the poorest worst? How public health cuts have been experienced in England's most deprived communities", available at: www.ippr.org/blog/publichealth-cuts

Kirby, T. (2020), "Evidence mounts on the disproportionate effect of COVID-19 on ethnic minorities", The Lancet/Respiratory Medicine, doi: 10.1016/S2213-2600(20)30228-9.

Marmot, M., Allen, J., Boyce, T., Goldblatt, P. and Morrison, J. (2020), Health Equity in England: The Marmot Review 10 Years on, UCL Institute of Health Equity, London.

Office for National Statistics ONS (2020a), "Deaths involving COVID-19 by local area and socio-economic deprivation: deaths occurring between 1 March and 31 May 2020", available at: www.ons.gov.uk/ peoplepopulationandcommunity/birthsdeathsandmarriages/deaths/bulletins/deathsinvolvingcovid 19 bylocalareasanddeprivation/deathsoccurringbetween1marchand31may2020

Office for National Statistics ONS (2020b), "Coronavirus (COVID-19) related deaths by ethnic group, England and Wales: 2 March 2020 to 10 April 2020", available at: www.ons.gov.uk/peoplepopulationandcommunity/ birthsdeathsandmarriages/deaths/articles/coronavirusrelateddeathsbyethnicgroupenglandandwales/ 2march2020to10april2020

Peace, S., Wahl, H.-W., Mollenkopf, H. and Oswald, F. (2007), "Environment and ageing", in Bond, J., Peace, S., Dittmann-Kohli, F. and Westerhof, G. (Eds), Ageing in Society, SAGE, London, pp. 209-234.

Phillipson, C. (2007), "The 'elected' and the 'excluded': sociological perspectives on the experience of place and community in old age", Ageing \& Society, Vol. 27, pp. 321-342, doi: 10.1017/ S0144686X06005629.

Platt, L. and Warwick, R. (2020), Are Some Ethnic Groups More Vulnerable to COVID-19 than Others?, The Institute for Fiscal Studies (Funded by Nuffield Foundation), London, available at: www.ifs.org.uk/ inequality/chapter/are-some-ethnic-groups-more-vulnerable-to-covid-19-than-others/

Prattley, J., Buffel, T., Marshall, A. and Nazroo, J. (2020), "Area effects on the level and development of social exclusion in later life”, Social Science \& Medicine (1982), Vol. 246, pp. 112722.

Public Health England (2020), Disparities in the Risks and Outcomes from Covid-19, PHE, London, available at: https://www.gov.uk/government/publications/covid-19-review-of-disparities-inrisks-and-outcomes

Rowles, G.D. (1978), Prisoners of Space? Exploring the Geographical Experience of Older People, Westview Press, Boulder, CO.

Scharf, T., Phillipson, C., Smith, A. and Kingston, P. (2002), Growing Older in Socially Deprived Areas: Social Exclusion in Later Life, Help the Aged, London.

Smith, R., Lehning, J. and Kyeongmo, K. (2018), "Aging in place in gentrifying neighborhoods: implications for physical and mental health", The Gerontologist, Vol. 58 No. 1, pp. 26-35.

Soja, E. (2010), Seeking Spatial Justice, University of MN Press, MN.

Thomése, F., Buffel, T. and Phillipson, C. (2018), "Neighbourhood change, social inequalities and age-friendly communities", in Buffel, T., Handler, S. and Phillipson, C. (Eds), Age-Friendly Cities and Communities: A Global Perspective, Policy Press, Bristol.

UK Parliament (2019), "Local government finance and the 2019 spending review", available at: https:// publications.parliament.uk/pa/cm201719/cmselect/cmcomloc/2036/203605.htm

United Nations (2020), "Policy brief: the impact of COVID-19 on women", available at: www.un.org/sites/ un2.un.org/files/policy_brief_on_covid_impact_on_women_9_apr_2020_updated.pdf 
Wiles, J.L., Leibing, A., Guberman, N., Reeve, J. and Allen, R.E. (2012), "The meaning of 'aging in place' to older people", The Gerontologist, Vol. 52 No. 3, pp. 357-366.

World Health Organization (2020), "Social stigma associated with COVID-19", available at: www.who.int/ docs/default-source/epi-win/stigma/covid19-stigma-guide.pdf

Yarker, S. (2019), Social Infrastructure: How Shared Spaces Make Communities Work, Ambition for Ageing and the University of Manchester, Manchester.

\section{Corresponding author}

Tine Buffel can be contacted at: tine.buffel@manchester.ac.uk

For instructions on how to order reprints of this article, please visit our website: www.emeraldgrouppublishing.com/licensing/reprints.htm

Or contact us for further details: permissions@emeraldinsight.com 